\title{
Potentials of AyURVEda AND medical PluRAlism
}

\section{P.Murali Krishna}

AYURVEDA an indigenous medical wisdom has its roots in Vedas and taking care of health needs of Indian society from time immemorial. It is a comprehensive health care system with well construed basic tenets, time tested formulary and unique Bio-purification technique (Pancha karma). This indigenous medical system literally called as 'Science of Life' give due importance to positive health care of individual by advocating special diet regimens, lifestyle regulations and drug administration suite to person, place and seasons. Its unique approach of treating the patients is individualized with threefold schedule of drug, diet and lifestyle to mitigate the entire disease process, thus restore the health.

The potential areas of Ayurveda in health and medical care management are as follows 1.' Rasayana', a class of drugs having the quality of slowdown the biological aging, and immuno-modulator effect. 2. Panchakarma, five types of Biopurificatory measures to eliminate the pathogens from the body through natural orifices and also to sensitize the body for subsequent drug therapies. 3. 'Kshara sutra' a para surgical technique of applying medicated thread in ano-rectal fistulae is well appreciated for its efficacy in healing the tracks and preventing the recurrence. 4. time tested and effective herbal and herbo-mineral formulae in the management of allergic skin \& respiratory diseases, acid-peptic disorders, IBS, Psoriasis, Auto-immune diseases, selective neurological disorders, Rhumatological diseases, Genito-urinary disease, male and female infertilities, Neuro-degenerative disorders, refractive errors of eye and migraine. Ayurveda has unique role in offering safe and effective remedies in management of above short listed conditions.

In the era of medical pluralism no system is absolute in catering the health needs of society. Openness, acceptability, honesty and patient oriented outlook which are very essential for any physician who has sole responsibility of safe guarding the health and life of patient. The physicians of Ayurveda, though they have special approach in diagnostics but depend on investigative procedures of contemporary modern medicine to have precision in diagnosis. In specific infective conditions like tuberculosis, intensive care, medical and surgical emergencies the patients are referred to specialists of modern medicine where an effective and life saving management can be expected. In growth disorders Homoeopathy has safe and cheap remedies. In specific skin disesases like vitiligo, Unani system has effective treatments. Siddha system has its unique role in offering quick and effective remedies with herbo- mineral combinations. All these medical system have their own way of medical care, which are unapproachable and incomprehensible to physicians of other systems. There is a need of openness and transparency of thought in exchanging the views among the physicians to offer most effective, safe and economy remedies for simple to fatal ailments. Carak Samhita, an Ayurvedic classic of Ancient India quotes that 'a team of doctors are best to evolve an undoubted remedies'. Every system has its own potential area and unique role in health and medical management. The greatness of these systems is segregated and pocketed. There is need to bring these potentials of various systems in to a common flat form and used for social application. The main short comings achieving medical pluralism in India are undue claims, lack of concern over patient, myopic thinking, commercialization and lack of class professionalism in practitioners. If we overcome these dark areas of thinking, medical pluralism and integrative approaches are going to offer safe, cheap and effective remedies to the needy.

\footnotetext{
* Dr P.Murali Krishna, M.D(Ay), Ph.D , Reader, PG Department of Panchakarma,

TTD's S.V.Ayurvedic College, Tirupati-517507(AP)
} 